\title{
GÊNEROS TEXTUAIS E FERRAMENTAS DIDÁTICAS PARA A FORMAÇÃO CONTIINUA DE PROFESSORES DE LÍNGUA PORTUGUESA
}

Elvira Lopes NASCIMENTO

UEL

Adair Vieira GONÇALVES

CEFORTEC/ NUTEAD/ UEPG

Cláudia Lopes Nascimento SAITO

CEFORTEC/NUTEAD/ UEPG

Resumo: Este artigo aponta dados de pesquisa desenvolvida na UEL que investiga as possíveis contribuições da metodologia de análise interacionista sociodiscursiva (BRONCKART, 2003; 2006) e da validade das ferramentas «modelo didático de gênero textual» e «seqüência didática», na forma como são concebidas pelo grupo de Didática de Línguas da UNIGE-Genebra/Suíça (DOLZ; SCHNEUWLY, 1997; e DOLZ et al, 2004) que têm sido produzidas por professores da rede pública das séries iniciais, do ensino fundamental. Apresentamos a síntese de resultados da análise dessas produções dos professores, após terem participado de curso de formação que se constitui em etapas distintas : a primeira, que recai sobre aspectos teóricos e metodológicos do interacionsismo sociodiscursivo e conceitos fundamentais bakhtinianos ; a segunda, sobre a transposição didática de gêneros textuais como ferramentas de mediação para as práticas de linguagem e a construção de materiais didáticos com os quais se pretende dar autonomia do professor em relação ao uso exclusivo dos livros didáticos. O artigo busca, primeiramente, (re)definir o conceito de modelo didático e apresentar um exemplo ilustrativo; em seguida, apresentar dados de análise de uma seqüência didática construída por professores das séries iniciais e reflexões sobre pontos críticos do processo de formação desses professores no momento da articulação das atividades de alfabetização e letramento.

Palavras-chave: gêneros textuais, transposição didática; modelo didático; formação de professor. 


\begin{abstract}
This article points partial data of research developed in UEL that investigates the possible contributions of the methodology of sociodiscursive interacionist analysis (BRONCKART, 2003; 2006) and of the validity of the tools "I model didactic of textual genre " and " didactic sequence ", in the form how they are conceived by the group of Didacticism of Languages of UNIGE-Geneva/Switzerland (DOLZ; SCHNEUWLY, 1997; DOLZ et al, 2004) that have been produced by teachers of the initial series of public schools, of the fundamental teaching. We will present the synthesis of results of the analysis of those productions of the teachers, after they have participated in formation course that is constituted in different stages: the first, that it relapses on theoretical and methodological aspects of the discursive interacionism and Bakhtin's fundamental concepts; The second, about the didactic transposition of textual genre as mediation tools for the language practices and the construction of didactic materials with which were intended to give the teacher's autonomy in relation to the exclusive use text books. The article wants, firstly, (re)define the concept of didactic model and to present an illustrative example; soon afterwards, to present data of analysis of a didactic sequence built by teachers of the initial series and reflections on critical points of the process of those teachers' formation in the moment of the articulation of the literacy activities and literacy.
\end{abstract}

Key words: Textual genre, didatic transposition, didactic model, teacher's training

\title{
Introdução
}

$\mathrm{Na}$ perspectiva do Interacionismo sociodiscursivo proposto por Bronckart (2006), entende-se a linguagem como um instrumento semiótico pelo qual o homem existe e age, o que implica interpretar os fatos de linguagem como "traços das condutas humanas socialmente contextualizadas" (BRONCKART, 2006). Integrando-se nas abordagens que enfocam as dimensões psicossociais das atividades de linguagem, o interacionismo sócio-discursivo (doravante ISD) admite que é pela "reapropriação, no organismo humano, dessas propriedades instrumentais e discursivas de um meio sócio-histórico" que se dá a emergência de capacidades conscientes que levam a uma ação de linguagem que se apresenta, externamente, como resultante da atividade 
social operada pelas avaliações coletivas e, internamente, como o produto da apropriação - pelo agente produtor - dos critérios dessa avaliação.

Nesse quadro epistemológico, Bronckart (2006, p. 122) toma a linguagem não somente como um meio de expressão estritamente psicológico, mas também a vê como "instrumento fundador e organizador" dos processos psicológicos nas suas dimensões estritamente humanas. Ou seja, em síntese, o ISD filia-se "a uma abordagem global e tendencialmente unificada do funcionamento psicológico, que toma como unidades de análise a linguagem, as condutas ativas (ou o "agir") e o pensamento consciente" (BRONCKART, 2006). Constata não só que "a atividade de linguagem se realiza concretamente sob a forma de textos, que são unidades semióticas e comunicativas contextualizadas, ou seja, mais ou menos adaptadas a certos tipos de interação humana" (BRONCKART, 2006, p. 104), senão também que tais textos se distribuem em gêneros diversos indexados no meio social e, sobretudo, agrupados num arquitexto de uma comunidade.

Citado por Bronckart como uma das fontes teóricas do interacionismo sociodiscursivo, Bakhtin define o gênero discursivo como "qualquer enunciado considerado isoladamente, individualizado, claro" (1934-35/1975), "um enunciado de natureza histórica, sóciointeracional, ideológica e lingüística", acrecentando que "a utilização da língua efetua-se em forma de enunciados (orais e escritos), concretos e únicos, que emanam dos integrantes duma ou doutra esfera da atividade humana"; assim, o conteúdo temático, o estilo e a construção composicional "fundem-se indissoluvelmente no todo do enunciado, e todos são marcados pela especificidade de uma esfera de comunicação". Os gêneros, segundo Bakhtin, organizam nossa fala e nossa escrita, assim como a gramática organiza as formas e em cada época e em cada grupo social há um repertório de discursos na comunicação sócioideológica.

No trabalho que temos desenvolvido para a formação de professores atuantes na Rede Pública de Educação Fundamental, temos nos deparado com o desafio de propor a eles o domínio da construção de ferramentas denominadas modelos didáticos (DOLZ; SCHNEUWLY, 1997/2004, p. 177) e seqüências didáticas (DOLZ; SCHNEUWLY, 1997; DOLZ et al, 2004) que possibilitem o seu uso em atividades de 
produção de materiais didáticos. O principal objetivo tem sido o de propiciar a esses professores a oportunidade para a discussão de propostas de construção de ferramentas didáticas que lhes possibilitem a autonomia dos livros didáticos e, ao mesmo tempo, enfoquem a linguagem das práticas sociais no contexto sociocultural em que se inserem.

Temos enfatizado, nos cursos de formação, a importância do estudo e da pesquisa sobre o gênero que será alvo da construção do modelo didático que possa indicar ao professor aquilo que seja adequado ensinar aos seus alunos. Isso significa que o modelo didático precisa se sustentar a partir do tripé : desconstrução, descrição e indicação das dimensões ensináveis do gênero. Salientamos, também, que o modelo descritivo do gênero não pode prescindir da abordagem dos diferentes níveis de análise, o que implica, a nosso ver, tanto as dimensões do processamento do texto verbal (oral ou escrito),como também as dimensões da linguagem visual, ou seja, dos aspectos não-verbais que se agregam tanto à escrita quanto à fala.

A circulação dos gêneros, conforme Saito $\left(2007\right.$, p. 23), ${ }^{1}$ sobretudo os veiculados nas mídias, tem tornado evidente que não podemos ignorar os textos multimodais, ou seja, aqueles que empregam duas ou mais modalidades semióticas em sua composição (palavras e

\footnotetext{
${ }^{1}$ Para a autora, é próprio de uma época tecnológica como a nossa que a sociedade se constitua através de uma diversidade de modos comunicativos que podemos classificar como "recursos semióticos" (imagens, sons, música, textura, traços, cores, etc.), que se combinam para produzir significados diversos, aos quais atribuímos valores (VOLOCHINOV, 1929-1977/1995) que são culturais e ideológicos e variam de acordo com o contexto da situação e com o propósito da comunicação.

${ }^{2}$ Saito (2007) salienta também que estudos teóricos na área da semiótica greimasiana (GREIMAS, 1970; 1974) e da Semiótica do Visual (FLOCH, 1985; 1990; 1991; 1995; 2001) podem contribuir para alargar os horizontes da teoria dos gêneros textuais / discursivos, desde que apontem para a questão abrangente da multimodalidade e do sincretismo de linguagens.

Essas abordagens lançam os analistas a um enfoque da relação semi-simbólica que se estabelece entre o plano do conteúdo e o de expressão dos gêneros que se constituem os gêneros multimodais e sincréticos permitindo, assim, um trabalho pedagógico significante, indispensável para a apreensão dos significados dos gêneros advindos das mídias e desenvolvimento das capacidades de leitura reflexiva e crítica em nossos alunos.
} 
imagens, por exemplo), o que resulta na noção de multimodalidade, ${ }^{2}$ assim como aqueles em que a significação emerge do imbricamento de linguagens, conhecidos como gêneros sincréticos.

Em nossa pesquisa, ${ }^{3}$ temos procurado incluir, no modelo de análise proposto pelo interacionismo sociodiscursivo, categorias de análise para a construção de modelos didáticos que abarquem os diferentes « recursos semióticos » dos gêneros focalizados, tendo em vista o desenvolvimento de capacidades que implicam multiletramentos. No presente artigo, vamos nos deter no encaminhamento proposto pela equipe de Genebra e pela metodologia de análise interacionista sociodiscursiva de Bronckart (2003; 2006) dos textos (verbais) que constituirão um modelo didático, procurando abarcar a questão da análise e descrição de gêneros textuais, tendo em vista a construção de materiais didáticos que dêem suporte às intervenções formativas com professores de língua portuguesa, das séries iniciais. Tais modelos didáticos e seqüencias didáticas (doravante $\mathrm{SDs}$ ) constituirão, desse modo, ferramentas importantes para o delineamento dos objetivos na didatização desses gêneros.

\footnotetext{
${ }^{3}$ Estamos nos referindo ao Projeto Integrado (Pesquisa/Ensino/Extensão, sob a coordenação da $\operatorname{Prof}^{a} \operatorname{Dr}^{a}$ Elvira Lopes Nascimento que apresenta, como objetivos principais: construir modelos didáticos de gêneros, descrevendo um corpus de textos em seus níveis contextuais e infratextuais; a partir dos modelos didáticos de gêneros, construir um acervo de ferramentas didáticas viabilizadas pelas seqüências didáticas a serem disponibilizadas para professores da rede pública; acompanhamento de professores da rede pública em sala de aula, para verificação de resultados obtidos no final da aplicação de seqüência didática através da triangulação de dados obtidos a partir da interação: professor ferramenta - aluno; verificando se houve avanço no nível de desenvolvimento dos alunos através da comparação das produções iniciais (antes da intervenção didática) e da produção final, depois da seqüência didática; os objetivos não alcançados pelo aluno quanto ao desenvolvimento de suas capacidades de ação, discursivas e lingüístico- discursivas aliadas às competências apontadas pelo MEC/SEB para as séries iniciais levam professores formadores e em formação à readaptação das seqüências didáticas para um retorno aos objetivos não atingidos na intervenção anterior, trabalho que exige reflexão e análise contínuas.
} 
$1 \mathrm{O}$ modelo didático: ferramenta preliminar para a didatização do gênero

A denominação "modelo didático" 4 surgiu em GenebraSuíça com o propósito definido de subsidiar o trabalho docente e favorecer o ensino/aprendizagem na compreensão/produção de textos em língua materna, neste caso, o francês. De acordo com o grupo de Genebra, para um ensino/aprendizagem de qualquer gênero de texto, faz-se necessário, antes, que as atividades em sala de aula sejam norteadas por um modelo didático do gênero. Segundo Schneuwly \& Dolz (1997, p. 7), um modelo didático, resumidamente, tem de apresentar duas características essenciais, quais sejam: $1^{\circ}$ ) "il constitue une synthèse à visée pratique, destinée à orienter les interventions des enseignants et $2^{\circ}$ ) il dégage les dimensions enseignables à partir desquelles diverses séquences didactiques peuvent être conçues". ${ }^{5}$ Dolz \& Schneuwly (2004) afirmam que o trabalho com SDs tem de estar fundamentado num modelo didático de gênero, modelo este que deve apontar aspectos centrais a serem trabalhados. Os autores afirmam que o modelo didático pode ser qualificado a priori, isto é, não levando em conta o nível dos estudantes nem as particularidades de uma turma (princípio da pertinência à turma em que o gênero será trabalhado).

\footnotetext{
${ }^{4}$ Para construção dos modelos didáticos, partimos, primeiramente, da pesquisa sobre o conhecimento acumulado pelos experts que nos fornecerão categorias de análise; da reflexão sobre o contexto imediato e sociohistórico de produção da prática social que configura o gênero; a partir daí, a análise da arquitetura interna dos textos do gênero (a infra-estrutura textual que compreende as três camadas do folhado textual: plano global do texto, tipos de discurso e organização seqüencial), a análise dos mecanismos de textualização (que compreende a conexão, a coesão nominal e a coesão temporal) e a análise dos mecanismos enunciativos e de modalização dos enunciados, instrumentos de análise da materialidade lingüística sempre em relação com a ação que a produz. Os elementos constitutivos da arquitetura textual são entendidos como resultantes das representações que os agentes constroem sobre a sua participação na atividade social que o fazem consciente de seu fazer e de sua capacidade de fazer.

5 "Ele constitui uma síntese prática, destinada a orientar as intervenções dos docentes e 2) ele esclarece as dimensões ensináveis a partir das quais diversas seqüências podem ser concebidas". (tradução nossa)
} 
De Pietro \& Schneuwly (2003) confirmam que o primeiro passo para ensinar um objeto qualquer é uma ferramenta chamada pela equipe de modelo didático. $\mathrm{O}$ modelo didático tem, segundo os autores citados, as seguintes características:

a) uma dimensão praxeológica;

b) uma força normativa (da qual, segundo os autores, é impossível fugir);

c) é o centro do processo de todo ensino e posterior aprendizagem;

d) pode ser implícito/intuitivo ou explícito e conceitualizado;

e) é o ponto de início e o ponto de chegada do trabalho a ser realizado;

f) é uma teoria mais genérica das atividades linguageiras;

g) é sempre o resultado de práticas de linguagens anteriores, portanto, históricas;

h) permite, a partir das práticas socias referenciais, produzir SDs ;

i) é o lugar de reflexões e práticas pedagógicas.

O grupo de Genebra intitula de práticas sociais de referência os textos empíricos produzidos por experts (em situações de congressos, seminários ou mesmo individualmente); os textos concretos de estudantes em situações de aprendizagem, já que estes servirão como ponto de partida para a construção da SD, e os exemplares de textos diversos e práticas escolares baseadas na aplicação/ensino de gêneros textuais nos seus diferentes contextos. Dolz e Schneuwly (2004) destacam que a construção de um modelo didático constitui a explicitação de hipóteses sobre certos dados, quais sejam: resultados de aprendizagem expressos/esperados em documentos oficiais; conhecimentos lingüísticos (entre estes, o funcionamento dos gêneros para os especialistas) e psicológicos; e, finalmente, a capacidade mostrada pelos estudantes.

Machado \& Cristovão (2006) afirmam, apoiando-se em De Pietro, do mesmo modo que, para que os objetivos do ensino/ aprendizagem de gêneros sejam alcançados, as práticas em sala de aula da produção de textos devem ser guiadas pelos modelos didáticos, os quais são objetos descritivos e operacionais que, quando construídos, facilitam a apreensão da complexidade da aprendizagem de um determinado gênero. Cristovão (2002) sustenta que o modelo permite 
visualizar as características do gênero em estudo/análise/produção e, sobretudo, facilita a seleção das dimensões ensináveis numa determinada etapa da escolarização ou o seu adiamento para etapas posteriores. Machado e Crsitovão (2006) complementam dizendo fazer-se necessário também conhecermos o estado da arte dos gêneros sobre o gênero e as prescrições oficiais sobre o trabalho docente. Cristovão e Nascimento (2004) salientam que, para a produção dos modelos didáticos torna-se fundamental analisar a infra-estrutura textual, os mecanismos de textualização e os mecanismos enunciativos. De Pietro \& Schneuwly (2003, p. 45) atestam que o modelo didático deve "être considéréé comme un processus collectif ininterrompu des didacticiens: tout modèle didactique [...] est toujors déjá résultat de ce processus et contribuition à son développment". ${ }^{6}$ Para os autores, o modelo didático pressupõe o ensino do saber, ele é, na sua essência, um modelo psicológico das capacidades a construir. Por outro lado, Dolz \& Schneuwly (2004) constatam uma espécie de normatização dos modelos didáticos em escolas francesas e suíças. Ele conclui que parte dos docentes petrifica, normatiza e estereotipa as SDs. Ainda assim, o autor constata que tal normatização faz parte da transição de um processo de desenvolvimento.

Dolz \& Schneuwly (2004) acrescentam que, para a caracterização detalhada do gênero, é necessária a coleta de textos autênticos, os quais, por sua vez, constituir-se-ão num corpus. Afirmam, principalmente, que quanto mais rico e variado for o corpus "mais a observação se estenderá a realizações textuais diversas correspondentes aos gêneros de textos trabalhados" (2004, p. 179). Assim, para controlar melhor o que será ensinado, o modelo didático serve como "um guia" das possibilidades ensináveis de um gênero. D. Pietro e Schneuwly (2003) assinalam que

Par ce terme (modèle didactique), nous designons le résultat de la description toujours provisoire des principales caractéristiques d'un genre dans la perspective de l'enseignement. Il sagit d'un construit théorique dont

\footnotetext{
6 “...ser considerado como um processo coletivo ininterrupto dos pedagogos: todo modelo didático, [...], já é sempre resultado deste processo e contribuição a seu desenvolvimento". (tradução nossa).
} 
l'elaboration repose sur des multiples choix complexes et qui, dans l'ingenierie didactique de l'enseignement de la langue maternelle, remplit plusieurs fonctions .?

Para os autores na mesma obra, o modelo didático é o produto de uma construção tripartite em interação e em evolução constantes: a legitimidade (saberes legitimados na esfera acadêmica), a pertinência (trata-se da mobilização dos saberes pertinentes tendo em vista objetivos e finalidades escolares) e, enfim, a solidarização (criação de um todo coerente em que os saberes são integrados formando sentidos novos), distanciando-se, dessa forma, do contexto teórico de que provieram. São, a nosso ver, os objetos potencializados para o ensino. Ou seja, parte-se do modelo didático, pede-se uma produção inicial e, em seguida, elabora-se a seqüência didática.

Bronckart (2003), ao tratar dos procedimentos metodológicos na utilização de gêneros em sala de aula, destaca a sua diversidade ilimitada e a sua variabilidade concreta, acarretando, por isso, determinados problemas metodológicos, entre eles a classificação, a identificação das características centrais do gênero. Bronckart destaca ainda que, para um estudo eficaz, devemos ter conhecimentos sobre o que estes gêneros são potencialmente, sob pena de efetuarmos um modelo didático equivocado. Ele acredita que a utilização de um conjunto de textos classificados como de gêneros diferentes facilita a identificação de suas características semelhantes/diferentes e favorece a construção do modelo didático, ainda que este não precise ser, teoricamente, perfeito e puro. Conseqüentemente, um modelo didático deve implicar a análise de um conjunto de textos (considerados do mesmo gênero) e deve implicar as três atividades do folhado textual de Bronckart, a saber, capacidades de ação, capacidades discursivas e as capacidades lingüístico-discursivas. ${ }^{8}$

\footnotetext{
7 "Por este termo (modelo didático), nós designanos o resultado da descrição sempre provisória das principais características de um gênero na perspectiva do ensino. Trata-se de um constructo teórico cuja elaboração recai sobre múltiplas escolhas complexas e que, na engenharia didática do ensino da língua materna, preenche várias funções". (tradução nossa)

${ }^{8}$ As capacidades de ação englobam o contexto físico da ação, o contexto social da interação comunicativa e o conhecimento de mundo que pode ser verbalizados
} 
Desse modo, entendemos o modelo didático como uma síntese prática que guia as ações do professor-pesquisador e, de outro lado, torna evidente aquilo que pode ser "ensinável" por meio de uma SD. Por ser descritivo, apreende o fenômeno complexo que é a aprendizagem de um gênero (anúncio publicitário, por ex.) orientando a pesquisa e, noutros contextos, norteia a prática docente. Na seqüência do artigo, apresentamos como pode se dar essa articulação entre o modelo didático e as atividades desenvolvidas na sala de aula.

\section{Um modelo didático para a organização da intervenção escolar}

Como já afirmamos, a descrição de um gênero deve abordar a esfera de comunicação que o delimita socio-historicamente e isso implica as relações entre instituições, lugares e papéis sociais e às suas representações; as representações do agir comunicativo que se deve empreender e o modo pelo qual esse agir pode se materializar no processo de textualização (as operações de linguagem verbal e nãoverbal).

Dito de outra maneira, o que importa apreender no gênero a ser didatizado é a regularidade do artefato sociocognitivamente construído, em relação à forma como se constitui a base pela qual o sujeito se orienta ao projetar o jogo de imagens entre os interlocutores (papéis sociais e comunicativos, motivações e intenções), assim como o espaço e o tempo da interação, e chegar à textualização, o que nos permite concebê-la como processo, produção e recepção, atividade co-construída por ações coordenadas dos participantes da interação.

Reconhecemos que seria impossível atingirmos, em um modelo didático, a abrangência de todos os aspectos que envolvem o fenômeno, mas como o objetivo é o de apreender e descrever qual é a forma regular (o estilo, os temas passíveis de por ele circularem e a

na ação; as capacidades discursivas referem-se ao estabelecimento de um tipo de ancoragem enunciativa (em conjunção ou disjunção em relação ao mundo ordinário da ação de linguagem); ao estabelecimento de um modo de apresentação dos conteúdos e à seleção e organização global e local dos conteúdos. Por fim, as capacidades lingüístico-discursivas são relativas à articulação de diferentes tipos de segmentos textuais, estabelecimento de relações entre as diferentes vozes expressão de posicionamentos sobre os enunciados. 
construção composicional) e o que poderia ser ensinável em um contexto escolar determinado, apresentamos como exemplificação do trabalho que temos realizado, o modelo didático do anúncio publicitário, justificando a escolha desse gênero pelo fato de que os discursos da publicidade fazem parte do cotidiano de todos nós.

Vale destacar ainda que, para a produção desse modelo didático, foram coletados anúncios publicitários da mídia impressa: Revista Veja e Folha de S. Paulo. Além disso, para a construção do modelo didático do gênero em questão, os integrantes do grupo consultaram vários autores que trabalham com a leitura e a produção desse gênero, entre os quais Carrascoza (1999), Gonzales (2003), Hoff \&Gabrielli (2004), Figueiredo (2005), Cidade (2006) entre outros.

\section{$2.1 \mathrm{O}$ modelo didático do anúncio publicitário: as dimensões ensináveis}

1. O contexto de produção: Em relação ao produtor dos textos, Vestergaard/Schroder (2000) citam o autor empírico do anúncio que é o publicitário - responsável pela textualização do texto, cujo papel social é o de funcionário de uma empresa de propaganda \& marketing, responsável pela campanha publicitária. O seu objetivo é o de convencer os leitores sobre as qualidades do produto, marca ou serviço. O lugar de produção é a empresa contratada para a campanha, onde o publicitário conta com uma equipe que se encarregará do dispositivo cênico para a organização da mensagem, de acordo com a natureza da mídia que lhe serve de suporte. O momento da produção do anúncio não é revelado explicitamente, mas pode ser inferido pela data da publicação da revista semanal que lhe serve de suporte. Considerando que o suporte influencia o gênero, o domínio discursivo de qualquer anúncio é a instância discursiva do discurso publicitário. Nenhum elemento do contexto físico de textualização é encontrado nos anúncios. $O$ produtor do texto não está relacionado à empresa que divulga, seu nome não aparece como emissor. A referência dêitica, quando presente nos textos, faz remissão à empresa que dirige a mensagem, responsável pelo conteúdo e facilmente localizável pelo destinatário, através do logotipo da empresa, na parte inferior ou superior do texto. Os destinatários, por sua vez, assim como o tempo e espaço de recepção são implicados no texto no momento da ação de 
linguagem em um tipo de publicidade "de proximidade", de ação direta, cujo perfil certamente já foi delineado pela revista que lhe serve de suporte.

2. O plano global dos textos: os anúncios publicitários (comerciais, institucionais ou sociais), apresentam as seguintes características : título, imagem, texto, marca, slogan. Mas, como se trata de um gênero bastante flexível, a maioria se apresenta com diferentes recursos semióticos (linguagem verbal, imagens, cores, formatos, de diagramação etc.). Além disso, alguns não apresentam títulos.

3. O tipo de discurso: a análise de alguns aspectos lingüísticodiscursivos ligados à ancoragem enunciativa e ao universo semântico e temático demonstram que há relativa presença de dêiticos de $1 .{ }^{a}$ pessoa (em $50 \%$ dos textos), e grande freqüência de dêiticos de $2 .^{a}$ pessoa. Também se observa grande freqüência de frases não-declarativas (imperativas, interrogativas, exclamativas e imperativas), indicando que o enunciador implica o destinatário e que, ao interagir explicitamente com ele, procura persuadi-lo. O discurso interativo é a sua estratégia de persuasão para posicionar-se como "amigo" que pode aconselhar, demonstrar e explicar o que afirma.

4. A coesão nominal: o próprio objeto anunciado (produto, marca ou serviço) vai servir de elemento isotópico para a instauração da coesão nominal. Por exemplo, temos a seguinte série no anúncio da Olympikus. "Olympikus. Patrocinadora oficial dos atletas do dia-adia. Patrocinadora oficial dos Jogos Rio 2007”. Aqui, temos coesão nominal por reiteração do mesmo elemento (Olympikus) e por elipse desse mesmo item. Por outro lado, temos anúncios em que a coesão é feita por frases de situação. Na publicidade, a frase de situação é aquela em que seu conteúdo temático só é interpretado pelo destinatário quando este associa o texto verbal ao não verbal. No anúncio do corpus, temos : "Este Motorola é tão moderno que já vem vestido de pink". O sintagma "Este Motorola" só é coesivamente interpretado quando se associa à imagem do aparelho celular da mesma companhia. A coesão nominal ocorre sob as mais diversas formas : reiteração do mesmo item lexical, por elipse, por pronominalização, por adverbialização, etc. As formas de coesão parecem reiterar a multimodalidade de linguagens freqüentemente associadas nos anúncios. 
5. A coesão verbal: predominam, em todos os anúncios do corpus, o modo imperativo seja para aconselhar, seja para direcionar "uma ordem de consumo" ou até mesmo para tornar o agenteprodutor e destinatário mais próximos. Com relação à conexão, os organizadores lógico-discursivos, em todos os anúncios que serviram de corpus, estão marcados implicitamente.

6. As instâncias de enunciação (vozes): na cena enunciativa definida pelos textos do gênero, é a voz da instituição/empresa, textualizada por um expositor (publicitário) dirigindo-se aos destinatários para mostrar e explicar como, através das ações por ela engendradas, consegue "fazer o bem" ao destinatário por dar-lhe informações sobre produtos, marcas ou serviços que o tornarão mais feliz/jovem/confortável etc., ainda que cada texto o faça criando cenografias variadas.

\section{Dos modelos didáticos à construção de SDs: a instrumentalização do professor para a construção de materiais didáticos}

Como já afirmamos, o modelo didático do gênero é resultante da primera fase da formação de professores, cujo objetivo é o de construir conhecimento sobre as práticas de linguagem situadas em diferentes esferas, sobre a concepção de linguagem sociointeracionista, sobre o contexto de ensino-aprendizagem de língua materna e sobre os gêneros textuais passíveis de serem didatizados nas séries iniciais. Na segunda fase do curso de formação, os professores passam à elaboração de materiais didáticos, baseados nos modelos didáticos já construídos pelos grupos.

Neste item, damos início à apresentação de dados resultantes da análise de uma SD construída por um grupo de professoras das séries iniciais, cuja formação é proporcionada pelo curso de Pedagogia. Selecionamos a SD sobre anúncios publicitários (que partiu de elementos «ensináveis» que foram apontados pelo modelo didático do tópico anterior). Selecionamos essa SD, porque intencionamos demonstrar em que medida os professores das séries iniciais selecionam e adaptam o modelo didático para o contexto específico de sua atuação docente ( $1^{\mathrm{a}}$ a $4^{\mathrm{a}}$ séries). 
O modelo descritivo do gênero construído pelo grupo de professoras forneceu a base para a elaboração das seqüências didáticas, estando cientes que havia a necessidade de buscar as dimensões ensináveis do gênero que pudessem atender às reais necessidades dos alunos, em relação aos conteúdos a "Introduzir, Trabalhar, Retomar e Consolidar" (SEB/MEC, 2004). Como na segunda fase do curso os professores construíram conhecimentos sobre a organização das etapas da organização modular da SD, conforme apontadas por Dolz et al. (2004), que compreendem, desde a apresentação de uma situação específica de comunicação, à produção inicial pelos alunos, a etapa de reconhecimento do gênero, as capacidades implicadas na leitura e na produção, nas operações lingüístico-discursivas, na organização dos elementos ensinados sobre o gênero em uma "lista de constatação", na auto-avaliação, na avaliação entre pares e coletiva, na refacção dos textos produzidos e, por fim, a reescrita do texto da produção inicial.

Tal organização modular de uma SD permite ao professor a triangulação de dados advindos de três momentos do processo: 1 . análise dos textos dos alunos na produção inicial ; 2. análise de textos dos alunos ao final da SD, quando surge o momento de completar a situação de interlocução instaurada pelos textos produzidos; 3 . os objetivos alcançados ou não alcançados em relação às capacidades a serem desenvolvidas nos cinco eixos preconizados pelo MEC/SEB.

4.1 Os pontos críticos para o processo de formação de professores das séries iniciais: a articulação de ações didáticas para alfabetização e letramento

O nosso desafio para a elaboração de seqüências didáticas junto a professores das séries inciais $\left(1^{\mathrm{a}}\right.$ a $\left.4^{\mathrm{a}}\right)$, deve-se ao fato de que temos de ficar atentos para que, nas atividades propostas, fiquem articulados os dois processos complementares e não alternativos para o "alfabetizar letrando" (DE SOUZA, 2001). Começando pelas capacidades a serem desenvolvidas nos aprendizes, é preciso observar, no trabalho elaborado por esses professores, a migração/ adaptação das capacidades sintetizadas por Guimarães (2006) em direção às capacidades, competências e atitudes a serem desenvolvidas na Educação Básica (MEC/SEB), articulando atividades em torno dos cinco eixos mais relevantes ao Primeiro Ciclo: 1. compreensão e valorização da 
cultura da escrita; 2. apropriação do sistema de escrita; 3 . leitura; 4. produção de textos escritos; 5 . desenvolvimento da oralidade. para a leitura e para a produção, que podem ser visualizadas no quadro a seguir:

Quadro 1 - Capacidades, conhecimentos e atitudes: a leitura (SEB/MEC, ano 2006)

\begin{tabular}{|c|c|c|c|}
\hline $\begin{array}{c}\text { CAPACIDADES, CONHECIMENTOS E } \\
\text { ATITUDES } \\
\text { (LEITURA) }\end{array}$ & $1^{\mathrm{a}}$ & $2^{a}$ & $3^{\mathrm{a}}$ \\
\hline $\begin{array}{l}\text {-Desenvolver atitudes e disposições favoráveis à } \\
\text { leitura }\end{array}$ & $\mathrm{I} / \mathrm{T} / \mathrm{C}$ & $\mathrm{T} / \mathrm{C}$ & $\mathrm{T} / \mathrm{C}$ \\
\hline - Desenvolver capacidades de decifração: & $\mathbf{I}$ & $\mathrm{T} / \mathrm{C}$ & $\mathrm{T} / \mathrm{C}$ \\
\hline i) saber decodificar palavras & $\mathbf{I}$ & $\mathrm{T} / \mathrm{C}$ & $\mathrm{T} / \mathrm{C}$ \\
\hline ii) saber ler reconhecendo globalmente as palavras & I & $\mathrm{T} / \mathrm{C}$ & $\mathrm{T} / \mathrm{C}$ \\
\hline - Desenvolver fluência em leitura & $\mathbf{I}$ & $\mathbf{T}$ & $\mathrm{T} / \mathrm{C}$ \\
\hline - Compreender textos & $\mathrm{I} / \mathrm{T} / \mathrm{C}$ & $\mathrm{T} / \mathrm{C}$ & $\mathrm{T} / \mathrm{C}$ \\
\hline $\begin{array}{l}\text { i) identificar finalidades e funções da leitura, em } \\
\text { função do reconhecimento do suporte, do gênero } \\
\text { e da contextualização do texto }\end{array}$ & $\mathrm{I} / \mathrm{T} / \mathrm{C}$ & $\mathrm{T} / \mathrm{C}$ & $\mathrm{T} / \mathrm{C}$ \\
\hline $\begin{array}{l}\text { ii) antecipar conteúdos de textos a serem lidos em } \\
\text { função de seu suporte, seu gênero e sua } \\
\text { contextualização }\end{array}$ & $\mathrm{I} / \mathrm{T} / \mathrm{C}$ & $\mathrm{T} / \mathrm{C}$ & $\mathrm{T} / \mathrm{C}$ \\
\hline $\begin{array}{l}\text { iii) levantar e confirmar hipóteses relativas ao } \\
\text { conteúdo do texto que está sendo lido (checar } \\
\text { hipóteses) }\end{array}$ & $\mathrm{I} / \mathrm{T} / \mathrm{C}$ & $\mathrm{T} / \mathrm{C}$ & $\mathrm{T} / \mathrm{C}$ \\
\hline $\begin{array}{l}\text { iv) buscar pistas textuais, intertextuais e } \\
\text { contextuais para ler nas entrelinhas (fazer } \\
\text { inferências), ampliando a compreensão (sua } \\
\text { estrutura composicional; os recursos linguísticos } \\
\text { que emprega; os recursos expressivos e os } \\
\text { recursos literários a que recorre;) }\end{array}$ & $\mathrm{I} / \mathrm{T} / \mathrm{C}$ & $\mathrm{T} / \mathrm{C}$ & $\mathrm{T} / \mathrm{C}$ \\
\hline $\begin{array}{l}\text { v) construir compreensão global do texto lido, } \\
\text { unificando e inter-relacionando informações } \\
\text { explícitas e implícitas }\end{array}$ & $\mathrm{I} / \mathrm{T} / \mathrm{C}$ & $\mathrm{T} / \mathrm{C}$ & $\mathrm{T} / \mathrm{C}$ \\
\hline $\begin{array}{l}\text { vi) avaliar ética e afetivamente o texto, fazer } \\
\text { extrapolações. }\end{array}$ & $\mathrm{I} / \mathrm{T} / \mathrm{C}$ & $\mathrm{T} / \mathrm{C}$ & $\mathrm{T} / \mathrm{C}$ \\
\hline
\end{tabular}

Fonte: Proletramento. Fascículo 1

Leia-se: $\mathbf{I}=$ introduzir $\mathbf{T}=$ trabalhar $\mathbf{R}=$ retomar $\mathbf{C}=$ consolidar 
Podendo-se observar a noção de gênero textual implícita e explicitamente subjacente a cada um dos itens apresentados, como também no quadro a seguir, referente às capacidades, conhecimentos e atitudes para a produção de textos escritos :

Quadro 2 - Capacidades, conhecimentos e atitudes: produção de textos escritos (SEB/MEC, ano 2006)

\begin{tabular}{|l|c|c|c|}
\hline \multicolumn{1}{|c|}{$\begin{array}{c}\text { CAPACIDADES,CONHECIMENTOS E } \\
\text { ATITUDES } \\
\text { (PRODUÇÃO DE TEXTOS ESCRITOS) }\end{array}$} & $\mathbf{1}^{\mathrm{a}}$ & $\mathbf{2}^{\mathbf{a}}$ & $\mathbf{3}^{\mathrm{a}}$ \\
\hline $\begin{array}{l}\text { Compreender e valorizar o uso da escrita com } \\
\text { diferentes funções, em diferentes gêneros }\end{array}$ & I/T/C & T/C & T/C \\
\hline $\begin{array}{l}\text { Produzir textos escritos de gêneros diversos, } \\
\text { adequados aos objetivos, ao destinatário e ao contexto } \\
\text { de circulação: }\end{array}$ & I & T/C & T/C \\
\hline $\begin{array}{l}\text { i) dispor, ordenar e organizar o próprio texto de } \\
\text { acordo com as convenções gráficas apropriadas }\end{array}$ & I & T/C & T/C \\
\hline $\begin{array}{l}\text { ii) Escrever segundo o princípio alfabético e as regras } \\
\text { ortográficas }\end{array}$ & I/T/C/ & T/C & T/C \\
\hline $\begin{array}{l}\text { iii) Planejar a escrita do texto considerando o tema } \\
\text { central e seus desdobramentos }\end{array}$ & I/T/C & T/C & T/C \\
\hline $\begin{array}{l}\text { iv) Organizar os próprios textos segundo os padrões } \\
\text { de composição usais na sociedade }\end{array}$ & I/T/C & T/C & T/C \\
\hline $\begin{array}{l}\text { v) Usar a variedade lingǘstica apropriada à situação } \\
\text { de produção e de circulação, fazendo escolhas } \\
\text { adequadas quanto ao vocabulário e à gramática. }\end{array}$ & I/T/C & T/C & T/C \\
\hline $\begin{array}{l}\text { vi) Usar recursos expressivos (estilísticos e literários) } \\
\text { adequados ao gênero e aos objetivos do texto }\end{array}$ & I/T/C & T/C & T/C \\
\hline $\begin{array}{l}\text { vii) Revisar e reelaborar a própria escrita, segundo } \\
\text { critérios adequados aos objetivos, aos destinatários e } \\
\text { ao contexto de circulação previstos. }\end{array}$ & I & T & T/C \\
\hline
\end{tabular}

Fonte: Proletramento. Fascículo 1

Leia-se: $\mathbf{I}=$ introduzir $\mathbf{T}=$ trabalhar $\mathbf{R}=$ retomar $\mathbf{C}=$ consolidar

Nas séries iniciais, para atender aos objetivos acima expostos, a forma como os professores elaboram a adaptação das capacidades apontadas por Schneuwly aos eixos para o Ciclo Básico, pode ser visualizada no quadro a seguir: 


\begin{tabular}{|c|c|c|}
\hline & Operações & Níveis de análise \\
\hline $\begin{array}{l}\text { Capacidades } \\
\text { de ação }\end{array}$ & $\begin{array}{l}\text { 1. Mobilização de representa- } \\
\text { ções sobre: } \\
\text { - o contexto físico da ação; } \\
\text {-o contexto social da interação } \\
\text { comunicativa: o destinatário, os } \\
\text { objetivos, o suporte de circulação; } \\
\text {-o contexto subjetivo constituído } \\
\text { pela relação social entre os parceiros } \\
\text { da interação: formal? informal? } \\
\text {-o tema central e seus } \\
\text { desdobramentos; } \\
\text { - conhecimento de mundo que } \\
\text { podem ser verbalizados na ação } \\
\text { situada: } \\
\text { - os símbolos, imagens, gêneros } \\
\text { textuais diferentes para localizar } \\
\text { informações }\end{array}$ & $\begin{array}{l}\text { 1. Levantamento de hipóteses sobre } \\
\text { as representações. } \\
\text {-Quem produz texto nesse gênero? } \\
\text { - Com que finalidade produz o teto? } \\
\text { - Sobre o quê / tema os textos desse } \\
\text { gênero tratam? } \\
\text { - Para quem se dirige/destinatário? } \\
\text { - Qual as imagens sociais de uns e } \\
\text { outros? } \\
\text { - Com qual propósito o agente produtor } \\
\text { realiza a sua ação de linguagem } \\
\text { recorrendo asse instrumento? } \\
\text { - Qual o valor desse gênero na } \\
\text { sociedade? } \\
\text { - Que valores por ele circulam em relação } \\
\text { ao tema? } \\
\text { - Como se pode projetar os sentidos do } \\
\text { texto para outras realidades ou } \\
\text { vivências? } \\
\text { - Que inferências e hipóteses podem ser } \\
\text { levantadas a partir das entrelinhas? } \\
\text { - Que conteúdos do texto podem ser } \\
\text { antecipados em função de seu suporte, } \\
\text { seu gênero e sua contextualização } \\
\text { - Que pistas textuais, intertextuais e } \\
\text { contextuais permitem a antecipação de } \\
\text { conteúdos do texto? }\end{array}$ \\
\hline $\begin{array}{l}\text { Capacidades } \\
\text { discursivas }\end{array}$ & $\begin{array}{l}\text { 1. Controle da estruturação } \\
\text { discursiva } \\
\text { estabelecimento de um tipo de } \\
\text { ancoragem enunciativa (em } \\
\text { conjunção ou disjunção em relação } \\
\text { ao mundo ordinário da ação de } \\
\text { linguagem): NARRAR OU EXPOR ? } \\
\text { o padrão de composição usual na } \\
\text { sociedade; } \\
\text { seleção e organização global e } \\
\text { local dos conteúdos temáticos; } \\
\text { estabelecimento de um modo de } \\
\text { apresentação do tema (estilo do } \\
\text { gênero) }\end{array}$ & $\begin{array}{l}\text { 2. Análise da infraestrutura } \\
\text { textual: } \\
2.1 \text { dos tipos de discurso e sua } \\
\text { articulação (relato interativo, narração, } \\
\text { expor teórico ou expor interativo); } \\
\text { 2.2 do plano global do texto; } \\
2.3 \text { da organização seqüencial ; } \\
2.4 \text { para formular julgamentos e } \\
\text { críticas; identificar tese e argumentos; } \\
\text { identificar o ponto de vista do } \\
\text { enunciador ou de personagem; } \\
\text { identificar efeitos de sentido decorrente } \\
\text { da utilização de recursos gráficos, } \\
\text { seleção lexical, repetição. }\end{array}$ \\
\hline
\end{tabular}




\begin{tabular}{|c|c|c|}
\hline $\begin{array}{l}\text { Capacidades } \\
\text { lingüístico- } \\
\text { discursivas }\end{array}$ & $\begin{array}{l}\text { 1. Textualização } \\
\text { - Articulação e coesão entre } \\
\text { diferentes partes do texto: } \\
\text { passagem de narração, de } \\
\text { descrição, de relato, de } \\
\text { argumentação, de exposição } \\
\text { teórica; } \\
\text { - seleção lexical da variante } \\
\text { lingüística adequada ao contexto } \\
\text { - Estabelecimento de estratégias } \\
\text { visuais ou sonoras } \\
\text { - seleção de recursos expressivos } \\
\text { (estilísticos) adequados ao gênero }\end{array}$ & $\begin{array}{l}\text { 3. Análise dos mecanismos de } \\
\text { textualização: } \\
\text { 3.1. da conexão, coesão nominal e } \\
\text { verbal } \\
\text { 3.2. dos mecanismos de inserção de } \\
\text { vozes } \\
\text { 3.3. dos mecanismos de modalização } \\
\text { 3.4. estruturação sintática dos } \\
\text { enunciados. } \\
\text { 3. 5.escrever segundo o princípio } \\
\text { alfabético e as regras ortográficas acordo } \\
\text { com as convenções gráficas apropriadas. } \\
\text { 3. 6. o uso de variedade lingüística } \\
\text { apropriada à situação de produção e de } \\
\text { circulação, fazendo escolhas adequadas } \\
\text { quanto ao vocabulário e à gramática; } \\
\text { 3.7. reflexão sobre o uso da língua nos } \\
\text { textos lidos e revisão e refacção dos } \\
\text { texto produzidos pelo aluno; }\end{array}$ \\
\hline
\end{tabular}

\subsection{A SD elaborada por professores em formação continuada, séries iniciais}

O espaço deste artigo permite apenas que apresentemos os dados sobre as decisões tomadas pelos professores na forma como organizaram o trabalho didático. A síntese desses procedimentos está no quadro a seguir.

Quadro 5 - A SD produzida por professores das séries iniciais

\begin{tabular}{|c|c|}
\hline Seqüência Didática & Anúncio Publicitário \\
\hline $\begin{array}{l}\text { Apresentação de um } \\
\text { problema de } \\
\text { comunicação }\end{array}$ & Anúncios e panfletagem: Combate ao mosquito da dengue. \\
\hline Produção inicial & $\begin{array}{l}\text { Sim, houve. } \\
\text { Para iniciar o processo de avaliação formativa. }\end{array}$ \\
\hline $\begin{array}{l}\text { O movimento geral } \\
\text { da SD nos } 5 \text { eixos das } \\
\text { capacidades: } 1 . \\
\text { compreensão e } \\
\text { valorização da } \\
\text { cultura da escrita; } 2 \text {. } \\
\text { apropriação do } \\
\text { sistema de escrita; } 3 \text {. } \\
\text { leitura; } 4 \text {. produção } \\
\text { de textos escritos; } 5 \text {. } \\
\text { desenvolvimento da } \\
\text { oralidade. }\end{array}$ & $\begin{array}{l}\text { * reconhecimento dos temas do gênero: publicidade ou propaganda; } \\
\text { consumidor; consumismo; produto; marca. } \\
\text { * reconhecimento das práticas sociais nessa esfera de comunicação, } \\
\text { distinguindo-a de outras, como por exemplo, as práticas sociais na esfera de } \\
\text { comunicação da ciência, da criação artística, etc. } \\
\text { * valores estéticos, morais e éticos disseminados pela propaganda; } \\
\text { * as condições de produção, os suportes em que circula, o surgimento do } \\
\text { gênero, etc } \\
\text { * a linguagem nos textos do gênero: atividades envolvendo a pontuação, a } \\
\text { seleção de certas palavras, a construção sintática do slogan, o tempo expresso } \\
\text { no texto, a coesão nominal por retomadas anafóricas, a variante lingüística, etc. } \\
\text { * a coesão nominal por retomada, a coesão temporal, a pontuação nos textos do } \\
\text { gênero; uso de unidades fonoaudiológicas como rimas; } \\
\text { * uso de diferentes tipos de letras e símbolos gráficos, etc. }\end{array}$ \\
\hline
\end{tabular}




\begin{tabular}{|l|l|} 
& $\begin{array}{l}* \text { a leitura das imagens: os aspectos plásticos- cores, linhas, formas, } \\
\text { composições; e a leitura interpretativa, que atribui sentidos à imagem. } \\
* \text { a multimodalidade nos anúncios } \\
\text { * Exposição oral. } \\
\text { * Discussão oral }\end{array}$ \\
\hline Produção final & $\begin{array}{l}\text { Produção de textos: } \\
\text { revisão, reelaboração do texto escrito na produção inicial . } \\
\text { A interlocução completa: }\end{array}$ \\
& $\begin{array}{l}\text { O anúncio produzido será fixado no jornal mural, local de socialização } \\
\text { de textos produzidos pelos alunos. }\end{array}$ \\
\hline
\end{tabular}

O layout da seqüência didática produzida coletivamente permite antever que a direção adotada para a formação constituiu um caminho promissor, pois, à medida que conduzia à apropriação de novos conhecimentos, novas práticas e a construção de novos materiais didáticos, propiciou aos professores rupturas com o modo tradicional de organizar as atividades didáticas e organização do tempo na sala de aula. Ao assumirmos os aportes desenvolvidos por Dolz e Schneuwly (1998), no contexto da Didática de Línguas e da intervenção na educação, agregados aos postulados teórico-metodológicos de Bronckart (1999; 2006) sobre as questões referentes ao papel da linguagem no desenvolvimento humano, confirmaram-se as nossas expectativas, enquanto pesquisadores e professores-formadores, de que o desenvolvimento está intimamente relacionado ao contexto sóciocultural em que a pessoa se insere e que ele se processa de forma dinâmica e dialética através de rupturas e desequilibrios provocadores de contínuas reorganizações por parte do indivíduo.

O estudo e as discussões de questões teóricas sobre a linguagem, a interação em sala de aula, o entorno sócio-cultural da sala de aula, as orientações oficiais para as séries iniciais, as oficinas para construção conjunta de materiais, os seminários, os relatos individuais relacionados à aplicação do material didático, os constantes feedbacks provocados pelas reflexões no contexto de formação e a reelaboração das seqüências didáticas constituíram conjuntos de atividades que demonstram, ao menos em parte, o processo relacionado ao desenvolvimento dos indivíduos. Acreditamos que a continuidade de tais procedimentos e a análise, in loco, de resultados da aplicação das seqüências didáticas nas salas de aula possam trazer dados que demonstrem a necessidade de novas articulações entre a teoria e a prática e a busca de novos caminhos. 


\section{Resultados e considerações finais}

De acordo com nossa avaliação, na formação contínua sempre ronda o perigo de uma "gramaticalização" dos gêneros textuais, ou seja, o gênero como pretexto para ensinar gramática. Nas seqüências didáticas em que os professores, por razões diversas, enfocam diversos gêneros, articulados entre si pela relação temática observam-se em maior número questões generalizantes como: "A que gênero textual pertence esse texto?" sem que se apresentem atividades com o objetivo de reconhecimento dos gêneros.

Quando ocorre essa questão nas SD que enfocam um único gênero, observa-se que esse tipo de questão aparece no movimento de "reconhecimento dos textos do gênero", nas atividades que visam à exploração de aspectos do gênero. Isso indica que nesse ponto deve ser reforçada a assessoria aos professores em formação, no momento em que buscam construir o próprio material didático.

Observa-se, nesse ponto, um confronto que consideramos natural, entre aquilo que propomos nas transposições didáticas e as práticas efetivas dos professores. O curso de formação, na forma « oficial e legitimada » como se apresenta aos professores, sempre irá constituir um processo dialético em que as rupturas e deslocamentos provocarão resistência (pelas rupturas que provocam) e a esperada reorganização de estruturas mentais por parte dos professores. Outro ponto de confronto é a tendência observada de que, do movimento inicial de "reconhecimento dos textos do gênero", o professor passa à "análise lingüística", sem considerar que sempre se deve relacionar o contexto de produção (e tudo o que dele faz parte) às operações de linguagem efetuadas pelo produtor do texto.

Nesse sentido, consideramos importante construir, no professor, a representação de que, a elaboração de seqüência didática (SD)é um processo que implica, antes de tudo, a compreensão de que o sentido textual não está inscrito na superfície do texto, nem pode ser pré-estabelecido pelo produtor do texto ou imposto pelo leitor, mas está em permanente negociação no espaço social. No momento em que nos empenhamos mais fortemente na direção da didatização dessas noções, no curso de formação contínua de professores, essas tiveram maior repercussão no encaminhamento das atividades constitutivas das SDs. 
Por outro lado, salientamos que, para um ensino da língua materna, faz-se necessário, antes de o gênero entrar em sala de aula, a sua modelização. Sobretudo, é necessário um corpus de textos pertencentes ao gênero em análise, com a intenção de conhecer suas características centrais. É necessário também, além disso, o conhecimento sobre o estado da arte do gênero a ser transposto didaticamente em forma de seqüências didáticas, e mesmo o conhecimento sobre as dificuldades dos estudantes no gênero específico, além das experiências de ensino-aprendizagem, como afirma Nascimento (2004), vindas dos documentos oficiais.

Tais fatores conjuntamente ajudam a seleção dos objetivos do ensino do gênero a ser adaptado ao nível dos alunos e, em seguida, na organização das atividades que comporão as três capacidades descritas no modelo didático, quais sejam (de ação, discursivas e lingüístico-discursivas) que devem ser exploradas em sua SD.

As atividades organizadas pelo grupo de professores da rede pública em formação contínua deixam entrever que a elaboração coletiva de materiais didáticos na forma de modelos didáticos de gêneros textuais e, posteriormente, nas sequências didáticas, na forma como são adaptadas aos eixos preconizados para os diferentes ciclos da educação fundamental, constituem um lugar privilegiado para a construção de conhecimentos científicos para os professores pesquisadores, para os professores -formadores e para os professores em formação, um ponto de reflexão que permite a abordagem teórica e metodológica dos gêneros textuais nos processos de intervenção formativa.

\section{Referências}

BAKHTIN, M. Estética da criação verbal. Trad. por M. E. Galvão Gomes. 3. ed. São Paulo: Martins Fontes, 2000.

BRONCKART, J. P. Atividade de linguagem, discurso e desenvolvimento bumano. Campinas: Mercado de Letras, 2006.

- Atividades de linguagem, textos e discursos. Por um interacionismo sócio-discursivo. São Paulo: Educ, 2003. 
CIDADE, M. A. Redação publicitária: o que faltava dizer. São Paulo: Saraiva, 2006.

CARrascoZA, J. A. A evolução do texto publicitário. São Paulo: Futura, 1999.

COULTHARD, Carmen Rosa (Org.). Texts and practices: reading in critical discourse analysis. Londres: Routledge, 1996.

CRISTOVÃO, V. L. L. Modelo didático de gênero como instrumento para formação de professores. In: MEURER, J. L.; MOTTA-ROTH, D. Gêneros textuais: subsídios para o ensino da linguagem. Bauru: Edusc, 2002. p. 31-73.

Gêneros e ensino de leitura em LE: os modelos didáticos de gêneros na construção e avaliação de material didático. 2001. Tese (Doutorado em Lingüística Aplicada e Estudos da Linguagem) Pontifícia Universidade Católica, São Paulo.

.; NASCIMENTO, E. L. Modelos didáticos de gêneros: questões teóricas e aplicadas. In: (Org) Gêneros textuais: teoria e prática. Londrina: Moriá, 2004.

DOLZ, J.; SCHNEUWLY, B. Gêneros e progressão em expressão oral e escrita: elementos para reflexões sobre uma experiência suíça (francófona). In: SCHNEUWLY. B; DOLZ, J. Gêneros orais e escritos na escola. Trad. de Roxane Rojo e Glaís Sales Cordeiro. Campinas: Mercado de Letras, 2004.

.; L__ Les genres scolaires: des pratiques langagières aux objets d'enseignement. Repères, n. 15, p. 27-40, 1997.

DE PIETRO, J-F; SCNHEUWLY, B. Le modèle didactique du genre : un concept de l'ingénierie didactique. Théories-Didactique de la lectureÉcriture. Réseau Didactique, Université Charles-de-Gaulle: Lille, 2003. 
FIGUEIREDO, Celso. Redação publicitária: sedução pela palavra. São Paulo: Pioneira Thomson Learning, 2005.

FLOCH, J. M. Quelques positions pour una sémiotique visuelle. Le Bulletin, Paris, Groupe de Recherches Sémio-Linguistiques, v. 1, n. 4-5, p. 1-16, 2001.

. Identités visuelles. Paris: Presses Universitaires de France, 1995.

Petites mythologies de l'oiel et l'espirit: pour une sémiotique plastique. Paris: Hadés-Benjamins, 1991.

Sémiotique, marketing et communication. Paris: Presses Universitaires de France, 1990.

Petites mythologies de l'oil et de l'esprit. Paris: Hadés, 1985.

GONZALES, L. Linguagem publicitária: análise e produção. São Paulo: Arte \& Ciência, 2003.

GREIMAS, A . J. L'enonciation: une posture épistémologique. Significação - Revista Brasileira de Semiótica, Ribeirão Preto, n. 1, p. 925, 1974.

Du sens - essais sémiotiques. Paris: Du Seuil, 1970.

HOFF, T.; GABRIELLI, L. Redação publicitária. 3. ed. Rio de Janeiro: Elsevier, 2004.

GUIMARÃES, A. M. Construindo propostas de didatização de gênero: desafios e possibilidades. Linguagem em (Dis)curso, Tubarão, v. 6, n. 3, p. 347-374, set./dez. 2006.

MACHADO, A. R.; CRISTOVÃO, V. L. L. A construção de modelos didáticos de gêneros: aportes e questionamentos para o ensino de gêneros. Linguagem em (Dis)curso, Tubarão, v. 6, n. 3, set./dez. 2006. 
MINISTÉRIO DA EDUCAÇÃO. Secretaria de Educação Básica. 2004. Orientações Gerais. Rede Nacional de formação Continuada de Professores de Educação Básica. Centros de Pesquisa e Desenvolvimento da Educação.

NASCIMENTO, E. L. Gêneros textuais e ferramentas didáticas para o ensinoaprendizagem de Lingua Portuguesa, 2007. (no prelo)

- A transposição didática de gêneros textuais: uma proposta de trabalho. In: CRISTOVÃO, V. L. L.; NASCIMENTO, E. L. (Org) Gêneros textuais: teoria e prática. Londrina: Moriá, 2004.

SAITO, Claudia L. N. Nas teias do Homem-Aranha: um estudo do gênero discursivo "adaptação oficial de filme em quadrinhos". 2007. Tese (Doutorado em Filologia e Língua Portuguesa) - Universidade Estadual Paulista, Assis.

SCHNEUWLY, B. Gêneros e tipos de discurso: considerações psicológicas e ontogenéticas. In: ; DOLZ, J. Gêneros orais e escritos na escola. Trad. de Roxane Rojo e Glaís Sales Cordeiro. Campinas: Mercado de Letras, 2004. p. 21-39.

SOUZA, L. V. As proezas das crianças: das mal traçadas linhas aos textos de opinião. 2001. Tese (Doutorado em Lingüística Aplicada e Estudos da Linguagem) - Pontifícia Universidade Católica, São Paulo.

VESTERGAARD, T.; SCHRODER, K. A linguagem da propaganda. 4. ed. Trad. João Alves dos Santos. São Paulo: Martins Fontes, 2004.

VOLOCHINOV, M. Marxismo e filosofia da linguagem. Trad. Michel Lahud e Yara F. Vieira. São Paulo: Hucitec, 1995. 